\title{
Mitochondrial calcium uptake underlies ROS generation during aminoglycoside-induced hair cell death
}

\author{
Robert Esterberg, ${ }^{1,2}$ Tor Linbo, ${ }^{3}$ Sarah B. Pickett, ${ }^{3,4}$ Patricia Wu, ${ }^{1,2}$ Henry C. Ou, ${ }^{1,5}$ Edwin W. Rubel, ${ }^{1,2,4,6}$ and David W. Raible ${ }^{1,3,4}$ \\ Virginia Merrill Bloedel Hearing Research Center, ${ }^{2}$ Department of Otolaryngology-Head and Neck Surgery, and ${ }^{3}$ Department of Biological Structure, ${ }^{4}$ Neuroscience Graduate Program, \\ University of Washington, Seattle, Washington, USA. ${ }^{5}$ Seattle Children's Hospital, Seattle, Washington, USA. ${ }^{6}$ Department of Physiology and Biophysics, University of Washington, Seattle, Washington, USA.
}

\begin{abstract}
Exposure to aminoglycoside antibiotics can lead to the generation of toxic levels of reactive oxygen species (ROS) within mechanosensory hair cells of the inner ear that have been implicated in hearing and balance disorders. Better understanding of the origin of aminoglycoside-induced ROS could focus the development of therapies aimed at preventing this event. In this work, we used the zebrafish lateral line system to monitor the dynamic behavior of mitochondrial and cytoplasmic oxidation occurring within the same dying hair cell following exposure to aminoglycosides. The increased oxidation observed in both mitochondria and cytoplasm of dying hair cells was highly correlated with mitochondrial calcium uptake. Application of the mitochondrial uniporter inhibitor Ru360 reduced mitochondrial and cytoplasmic oxidation, suggesting that mitochondrial calcium drives ROS generation during aminoglycoside-induced hair cell death. Furthermore, targeting mitochondria with free radical scavengers conferred superior protection against aminoglycoside exposure compared with identical, untargeted scavengers. Our findings suggest that targeted therapies aimed at preventing mitochondrial oxidation have therapeutic potential to ameliorate the toxic effects of aminoglycoside exposure.
\end{abstract}

\section{Introduction}

Aminoglycosides are a widely used and successful class of antibiotics $(1,2)$. Despite their potent antimicrobial efficiency, all aminoglycoside antibiotics currently approved for use by the FDA are toxic to the kidney and inner ear. While nephrotoxic effects of aminoglycoside exposure are typically thought to be reversible, ototoxic effects are permanent, as they damage mechanosensory hair cells within the ear that, in mammals, lack the ability to regenerate.

A unifying mechanism of aminoglycoside-induced ototoxicity remains elusive, but a number of observations indicate that dying hair cells present several hallmarks that are conserved across species $(3-5)$. An event frequently implicated in the degeneration of hair cells is the generation of cytotoxic levels of reactive oxygen species (ROS), bioreactive molecules derived from molecular oxygen. Within the avian and rodent cochlea, elevated ROS levels have been detected within hair cells following aminoglycoside exposure (6-11). Augmentation with various antioxidants in vitro and in vivo has proven to be partially effective at ameliorating aminoglycoside ototoxicity (12-18), suggesting a causal link between ROS production and hair cell death. However, antioxidants generally do not protect across a wide range of antibiotic doses and do not distinguish between the origins of ROS, leaving the source of ROS production during aminoglycoside-induced hair cell death an open question.

There remains extensive debate over whether mechanisms governing bactericidal toxicity are shared within mammalian cell types that are also susceptible to these drugs. In bacteria, aminoglycosides induce oxidative damage through disruption of the citric acid cycle

Conflict of interest: The authors have declared that no conflict of interest exists. Submitted: October 2, 2015; Accepted: June 9, 2016.

Reference information: / Clin Invest. 2016;126(9):3556-3566. doi:10.1172/JCI84939. and electron transport chain $(19,20)$. Although the impact of ROS generation on bactericidal effects is unclear, it has been suggested that these antibiotics can induce cellular dysfunction within mammalian cells through mitochondrial generation of ROS (21). As mitochondria generally impose the largest influence to the overall oxidative state of the cell through their housing and regulation of the citric acid cycle and electron transport chain components $(22,23)$, they are a likely source of ROS during aminoglycoside-induced hair cell death.

ROS generated within mitochondria occur as the byproduct of metabolic activity, which is established in large part through $\mathrm{Ca}^{2+}$ signaling between endoplasmic reticulum and mitochondria (24). Mitochondrial $\mathrm{Ca}^{2+}$ regulates the flow of electron transport during oxidative phosphorylation (OXPHOS), and during the ensuing transfer of electrons, leakage at complexes I and III reduces $\mathrm{O}_{2}$ into superoxide $\left(\mathrm{O}_{2}{ }^{-}\right)$. This highly toxic yet membrane-impermeable anion is subsequently detoxified within mitochondria into less reactive, but membrane-permeable, hydrogen peroxide $\left(\mathrm{H}_{2} \mathrm{O}_{2}\right)(25,26)$.

Despite a link to ototoxicity, the source of ROS production following aminoglycoside exposure has remained largely unexplored. Here, we use the zebrafish lateral line system to study ROS generation and flow during hair cell death. Lateral line hair cells are sensitive to aminoglycosides $(27,28)$, and their external location in clusters, termed neuromasts, makes them uniquely suited to follow dynamic events during hair cell death in vivo $(29,30)$. We have previously used this system to observe intracellular $\mathrm{Ca}^{2+}$ dynamics following aminoglycoside exposure, and have demonstrated that mitochondrial $\mathrm{Ca}^{2+}$ influences mitochondrial activity in dying hair cells (31). In the experiments presented here, we have paired spectrally distinct indicators of mitochondrial oxidation state and cytoplasmic ROS to monitor temporal progression of oxidative changes following aminoglycoside exposure. We 
A

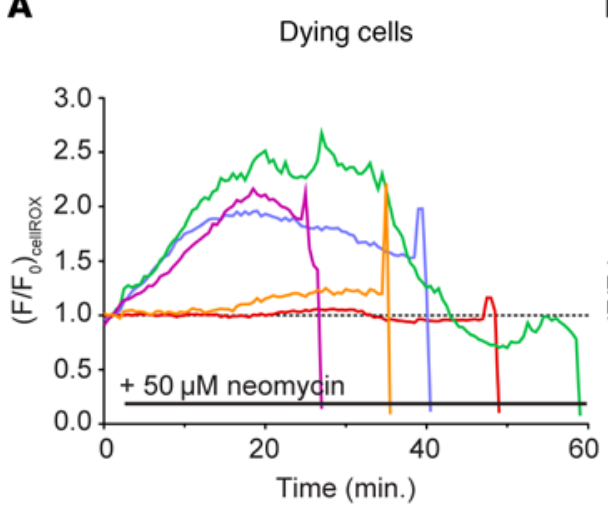

B

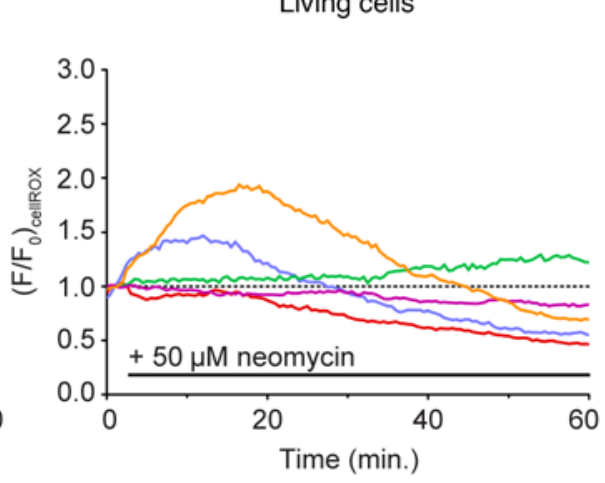

C
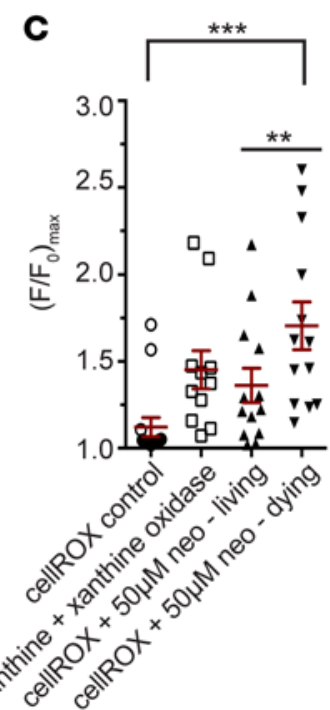

Figure 1. Oxidative changes in lateral line hair cells following aminoglycoside exposure monitored with cellROX. (A) Transformed ( $\left.F / F_{0}\right)$ fluorescence intensity data of individual cells loaded with cellROX that die following exposure to $50 \mu \mathrm{M}$ neomycin. Colors indicate individual hair cells. (B) Transformed $\left(F / F_{0}\right)$ fluorescence intensity data of individual cellROX-labeled cells that survive following exposure to $50 \mu \mathrm{M}$ neomycin. The dotted line in $\mathbf{A}$ and $\mathbf{B}$ represents $\left(F / F_{0}\right)$ of 1 , corresponding to preneomycin baseline levels. (C) Scatter plot of maximal cellROX fluorescence change in surviving or dying cells exposed to $50 \mu \mathrm{M}$ neomycin. Horizontal line and error bar represent the mean $\pm 1 \mathrm{SEM}$. One-way ANOVA, Holm-Šidák multiple comparison post-test; ${ }^{* *} P<0.01,{ }^{* * *} P<0.001$. Individual points in C are mean neuromast fluorescence taken from fewer than 5 cells per neuromast and 1 to 3 neuromasts per animal. $n=15$ (control), 11 (xanthine), 13 (neomycin, living), and 13 (neomycin, dying) neuromasts. Data from neomycin experiments (living versus dying) are paired data.

demonstrate that, in addition to elevated levels of ROS within cytoplasm, mitochondrial oxidative changes occur within dying lateral line hair cells exposed to aminoglycosides. Moreover, we demonstrate that elevated mitochondrial $\mathrm{Ca}^{2+}$ is necessary for both mitochondrial oxidation and cytoplasmic ROS observed during this process. Our data suggest that therapies aimed at preventing dramatic oxidative changes within mitochondria may be more effective at stemming aminoglycoside-induced hearing loss than other approaches using general ROS scavengers.

\section{Results}

Oxidation of specific cellular compartments occurs within dying lateral line hair cells following aminoglycoside exposure. To evaluate whether ROS was elevated within zebrafish lateral line hair cells following aminoglycoside exposure, we used the ROS indicator dye cellROX green, as it labels a number of intracellular compartments, including cytoplasm, nucleus, and mitochondria. We exposed zebrafish to $50 \mu \mathrm{M}$ neomycin, a concentration that reliably induces cell death in approximately $40 \%$ of hair cells within each neuromast (27), allowing us to compare the behavior of cellROX between adjacent living and dying cells in the same environment. Fluorescence of cellROX over background levels $\left(\mathrm{F} / \mathrm{F}_{0}\right)$ increased in most cells, regardless of their susceptibility to aminoglycosides (Figure 1, A and B). Cells were categorized as living or dying based on their fragmentation and clearance from the neuromast. Maximal fluorescence of dying cells was, however, greater than that of surviving cells by approximately $26 \%$, and $50 \%$ higher than that of controls $(P<0.05$; Figure 1C). Maximal fluorescence in surviving cells did not reach a level that was higher to a statistically significant degree than that of controls. In separate experiments, following addition of the superoxide generator xanthine oxidase and its substrate xanthine (32), cellROX fluorescence increased on average by $15 \%$ (Figure 1C) without inducing toxicity over the course of imaging (not shown), indicating the overall effectiveness of this indicator in detecting cell-wide changes in ROS.

Most dying cells displayed an increase in cellROX fluorescence in several intracellular structures, including the cytoplasm and nucleus (Figure 2 and Supplemental Video 1; supplemental material available online with this article; doi:10.1172/ JCI84939DS1). In contrast, an increase of cellROX fluorescence in cells that survived aminoglycoside exposure appeared to be largely non-nuclear (Figure 2).

CellROX reports nuclear and mitochondrial ROS generation through its ability to bind DNA. We reasoned that the non-nuclear changes we observed in cells reflected the interaction of cellROX with mitochondrial DNA, particularly as we previously reported a rapid increase in mitochondrial membrane potential $(\Delta \psi)$ in dying hair cells exposed to aminoglycosides (30). Given the interrelatedness between mitochondrial $\Delta \psi$ and mitochondrial ROS production (33), we tested whether the increased ROS observed in hair cells exposed to aminoglycosides correlated with increased mitochondrial activity, using transgenic zebrafish expressing the $\mathrm{H}_{2} \mathrm{O}_{2}$ biosensor HyPer (34) under the control of a hair cell-specific promoter (Tg[myo6b:HyPer]; referred to here as HyPer). The behavior of the HyPer biosensor alone in response to aminoglycoside exposure is shown in Supplemental Figure 2.

We colabeled hair cells of transgenic HyPer fish with tetramethyl rhodamine ester (TMRE), a red fluorescent indicator of $\Delta \psi(35)$, to monitor these events within the same cell. As we do not observe increased mitochondrial activity in hair cells that survive aminoglycoside exposure (30), we exposed hair cells to $400 \mu \mathrm{M}$ neomycin, a concentration that is toxic to all hair cells within the neuromast (27). 

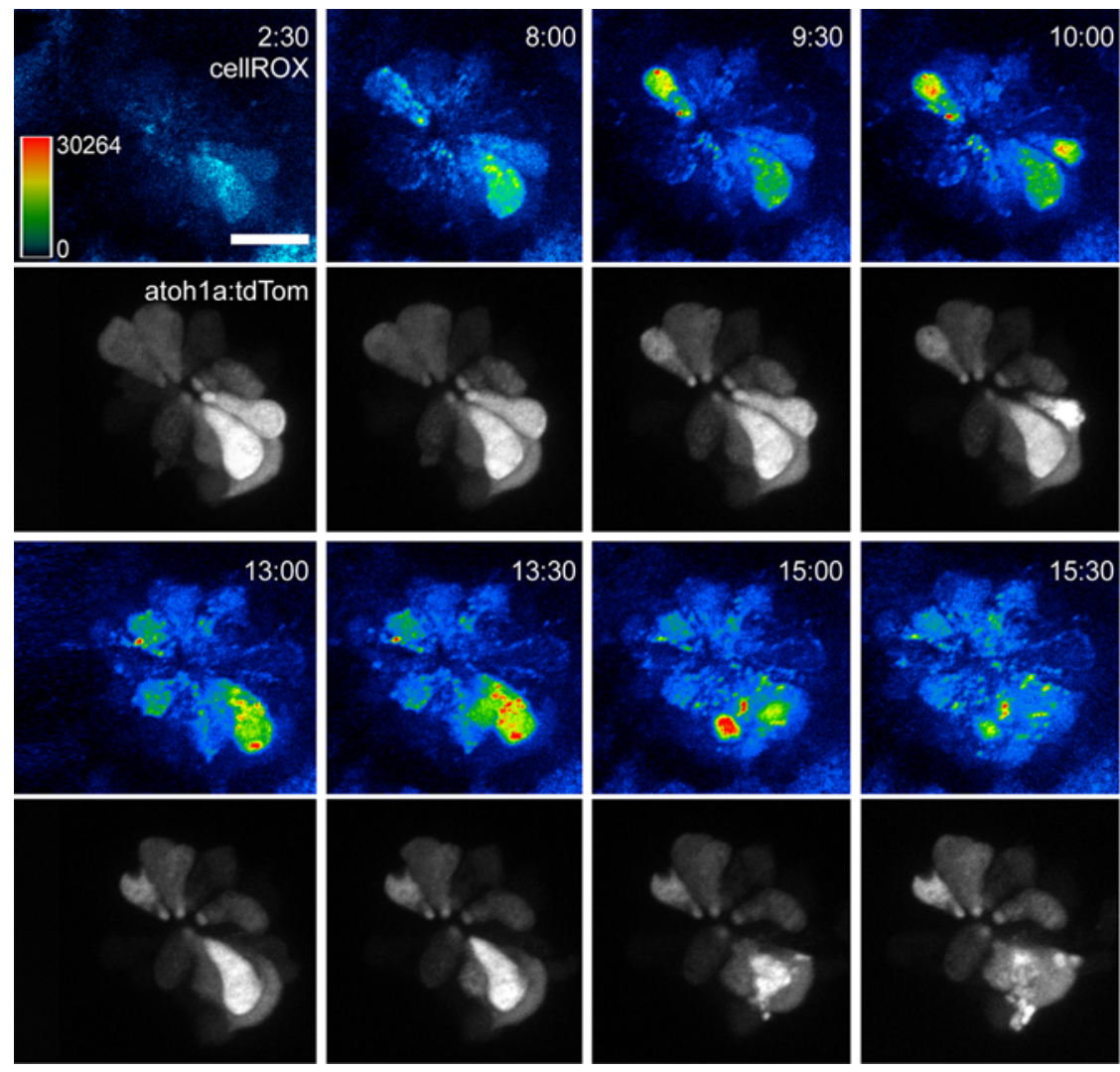
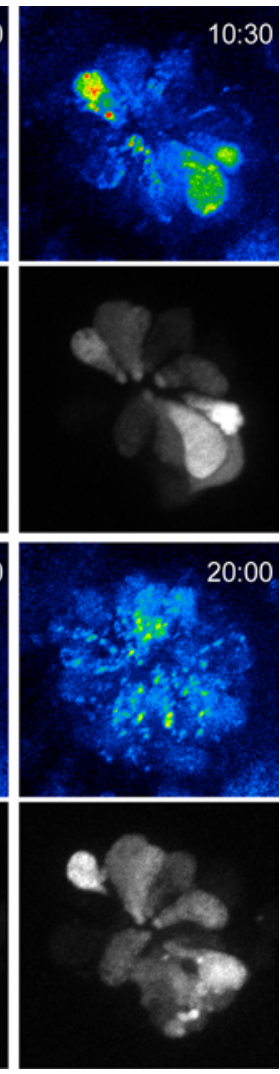

Figure 2. Oxidative changes within lateral line hair cells following aminoglycoside exposure. Sequential time-lapse images of a transgenic $\mathrm{Tg}$ (atoh1a: tdTomato)-labeled neuromast loaded with cellROX exposed to $50 \mu \mathrm{M}$ neomycin. CellROX panels are shown as heat-mapped, while tdTomato panels are shown in gray scale. These time-lapse panels are representative of 10 movies taken in this background, and of more than 50 movies taken in the background of nontransgenic, wild-type larvae. Time indicates minutes:seconds following neomycin exposure. Scale bar: $20 \mu \mathrm{m}$.

Paired HyPer and TMRE fluorescence data from individual dying cells were aligned to the point of mitochondrial depolarization that reliably occurs within dying cells (denoted as $\left.\mathrm{TMRE}_{\text {half-min }}\right)(30,36)$. As seen in Figure 3A, overall changes in HyPer fluorescence follow a time course similar to that of increases in TMRE fluorescence. We next asked whether the time of fluorescence onset for each indicator was correlated. Because both indicators are dynamic and reversible, we were able to perform cross-correlation analyses on data extracted from each cell to assess the time delay between the 2 signals. Our analysis indicated that TMRE fluorescence increased approximately 0 to 1 minute before increased HyPer signals (maximal $r$ for TMRE was 0 minutes relative to HyPer, where $r=0.401$, $P=0.011$; Figure 3B). These data support the idea that some ROS production is linked to increased mitochondrial activity.

To evaluate mitochondrial redox state during aminoglycoside exposure more closely, we loaded hair cells with the dye mitoSOX, a fluorescent indicator of mitochondrial oxidation (37) that is spectrally separable from TMRE. We initially characterized the behavior of mitoSOX alone in response to aminoglycoside exposure, and observed a robust increase in fluorescence of dying cells consistent with an oxidized mitochondrial matrix (Supplemental Figure 3). We then loaded both mitoSOX and TMRE into hair cells to monitor the relationship between mitochondrial oxidation and $\Delta \psi$. Paired mitoSOX and TMRE fluorescence data from individual dying cells aligned to the point of mitochondrial depolarization can be seen in Figure 4A; overall changes in mitoSOX fluorescence follow a time course similar to that of changes in TMRE fluorescence. Because mitoSOX signal is cumulative, with fluorescence remaining after ROS is dissipated, we could not perform meaningful cross-correlation analysis as we did for TMRE and HyPer. However, we observed a strong correlation between mitoSOX and TMRE for both the onset of increased fluorescence $(r=0.8918$, $P<0.0001$; Figure $4 \mathrm{~B})$ and maximal $\left(\mathrm{F} / \mathrm{F}_{0}\right)$ values $(r=0.8315$, $P<0.0001$; Figure $4 \mathrm{C}$ ). Together, these observations are consistent with the idea that mitochondrial activity and ROS production are coregulated in dying cells exposed to aminoglycosides.

Mitochondrial $\mathrm{Ca}^{2+}$ uptake is necessary for mitochondrial and cytoplasmic oxidation during aminoglycoside-induced hair cell death. Mitochondrial $\mathrm{Ca}^{2+}$ can drive ROS production through stimulation of mitochondrial activity $(33,38,39)$. We have previously shown that mitochondrial $\mathrm{Ca}^{2+}$ is increased within dying cells following aminoglycoside exposure in a manner resembling mitochondrial $\mathrm{Ca}^{2+}$ overload (36). To explore whether stimulation of mitochondrial activity by $\mathrm{Ca}^{2+}$ uptake could be responsible for driving cytoplasmic oxidation within dying hair cells, we combined spectrally distinct sensors to monitor their temporal progression. For this analysis we injected a transgenesis construct containing the red fluorescent $\mathrm{Ca}^{2+}$ indicator RGECO (40) targeted to mitochondria (Tg[myo6b:mitoRGECO]; referred to as mitoRGECO) (31) into transgenic HyPer fish. 


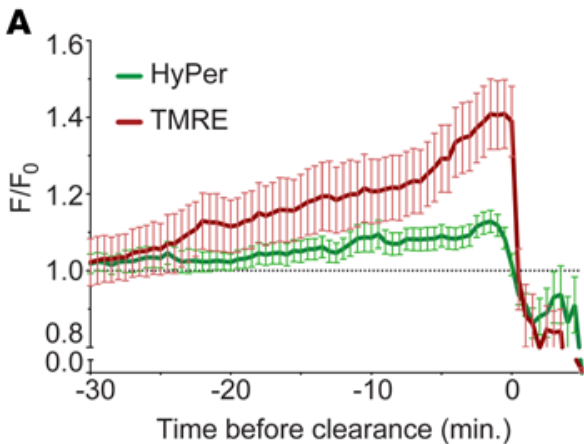

Figure 3. Timing of cytoplasmic oxidation (HyPer) relative to mitochondrial membrane potential (TMRE) in dying hair cells exposed to aminoglycosides. (A) Mean HyPer fluorescence in dying lateral line hair cells colabeled with TMRE and exposed to $400 \mu \mathrm{M}$ neomycin. Data are aligned to $T M R E_{\text {half-min }}$, corresponding to dye redistribution from mitochondria into cytoplasm. (B) Mean cross-correlation values of HyPer relative to TMRE. An offset of $t=0$ indicates that the events are inseparable. In this case, maximal cross-correlation value $(\mathrm{R})$ was at 0 minutes $(r=0.401, P=0.011)$, indicating that the initial onset of increased HyPer fluorescence coincides with the onset of increased TMRE fluorescence. Error bars = SEM; $n=39$ cells from 1 to 3 neuromasts per animal and 5 animals.
Changes in the behavior of paired mitoRGECO/HyPer fluorescence in dying hair cells are aligned to cell clearance and are shown in Figure 5A. Because both indicators are reversible, we performed cross-correlation analyses on data extracted from each cell to assess the time delay between the 2 signals. Our analysis indicated that mitoRGECO increased approximately 0 to 3 minutes before increased HyPer signals (maximal $r$ for mitoRGECO was at -1 minute relative to HyPer, where $r=0.411, P=0.013$; Figure $5 \mathrm{~B})$. These data support the idea that some of the oxidative changes observed in the cytoplasm originate in mitochondria, and suggest that the mitochondria ROS increase is driven by mitochondrial $\mathrm{Ca}^{2+}$ uptake.

To further examine the hypothesis that mitochondrial $\mathrm{Ca}^{2+}$ is responsible for oxidative changes during aminoglycoside-induced hair cell death, we inhibited mitochondrial $\mathrm{Ca}^{2+}$ uptake with the ruthenium red analog Ru360 (41). We have previously shown that Ru360 reduces aminoglycoside toxicity (31). As found previously, we observed that fewer cells died when pretreated with Ru360 before neomycin exposure (not shown). Of those cells that did die, maximal cellROX fluorescence was reduced by $29 \%$ in comparison with neomycin exposure alone $(P<0.05$; Figure $6 \mathrm{~A})$, indicating that ROS levels were reduced in these cells. We observed similar results with mitochondrial and cytoplasmic indicators; maximal mitoSOX fluorescence and HyPer fluorescence of dying cells were also reduced by $39 \%$ and $13 \%$, respectively (both $P<$ 0.05; Figure 6, B and C). Exposure to Ru360 also lowered HyPer maximal fluorescence in cells that survived neomycin exposure (both $P<0.05$ ). The overall reduction in fluorescence of these indicators in the presence of Ru360, together with the timing of HyPer behavior relative to mitoRGECO, is consistent with the hypothesis that mitochondrial $\mathrm{Ca}^{2+}$ uptake plays an important upstream role in the oxidative changes occurring in mitochondria and cytoplasm during aminoglycoside-induced hair cell death.

Mitochondrial-targeted ROS sinks are effective at mitigating aminoglycoside toxicity. We predicted that reducing ROS at their source would offer superior protection against aminoglycoside exposure when compared with a more ubiquitous ROS scavenging regimen. For this comparison we selected the superoxide scavengers TEMPOL and mitoTEMPO, a $\mathrm{TPP}^{+}$-conjugated version of TEMPOL $(42,43)$. The positive charge resulting from the TPP linkage is thought to enrich its presence in mitochondrial matrix 100 - to 1,000-fold (44). We first determined the optimal concentration for each compound that was maximally protective under conditions of neomycin exposure while also nontoxic when administered on its own (Figure 7A). We opted to use both compounds at $50 \mu \mathrm{M}$, since TEMPOL was slightly toxic to hair cells at increased concentrations. To determine the effectiveness at which these agents act as electron sinks, we incubated zebrafish larvae in either cellROX or mitoSOX while coexposing them to cyclosporin A (CsA). CsA induces mitochondrial oxidation via inhibition of the mitochondrial transition pore regulator cyclophilin D (45). CsA increased cellROX and mitoSOX fluorescence by $300 \%$ and $377 \%$, respectively, when com-
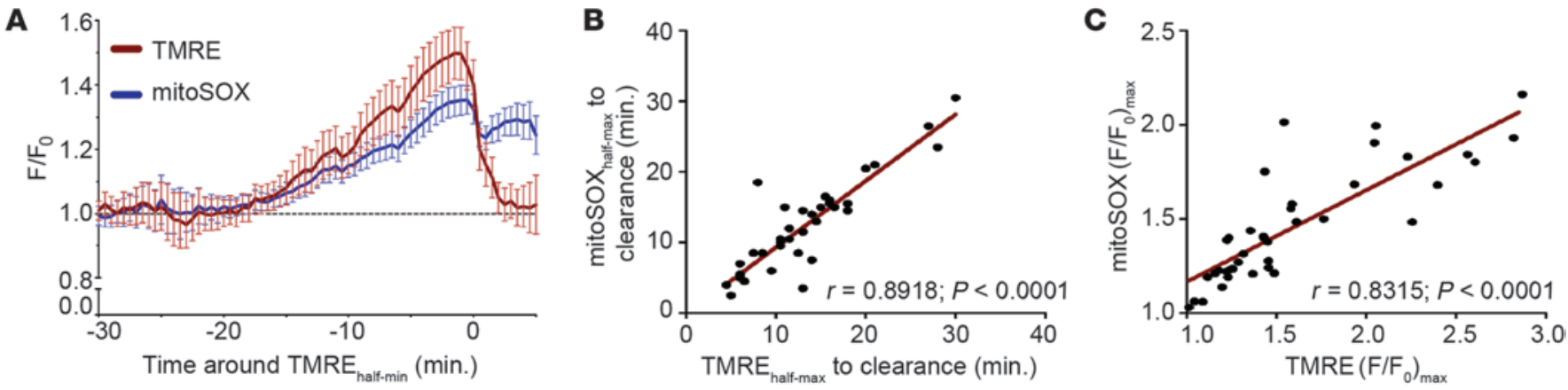

Figure 4. Timing of mitochondrial oxidation relative to mitochondrial membrane potential in dying hair cells exposed to aminoglycosides. (A) Mean mitoSOX fluorescence in dying lateral line hair cells colabeled with TMRE and exposed to $400 \mu \mathrm{M}$ neomycin. Data are aligned to TMRE ${ }_{\text {half-min' }}$ corresponding to dye redistribution from mitochondria into cytoplasm. (B) Relationship between maximal mitoSOX and TMRE fluorescence. Points represent paired maximal fluorescence data from individual cells. (C) Relationship between rise in fluorescence signal of mitoSOX and TMRE relative to cell clearance. Points represent paired data from the time that either indicator reached its half-maximal value relative to the time of cell clearance. Error bars = SEM; $n=39$ cells from 1 to 3 neuromasts per animal and 6 animals. 
A

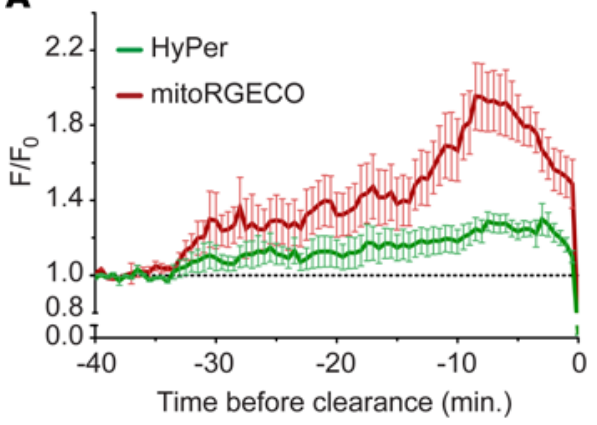

B

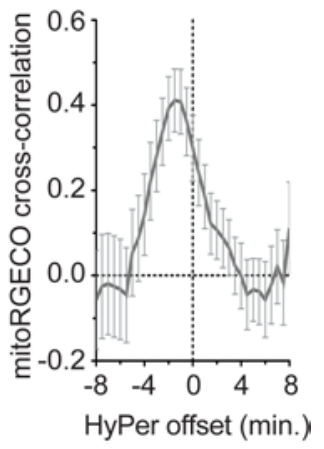

Figure 5. Cytoplasmic oxidation (HyPer) is correlated with mitochondrial $\mathrm{Ca}^{2+}$ uptake (mitoRGECO) during aminoglycoside-induced hair cell death. (A) Mean transformed $\left(F / F_{0}\right)$ intensity of HyPer and mitoRGECO within dying hair cells exposed to $400 \mu \mathrm{M}$ neomycin aligned to the time at which they are cleared from the neuromast. The dashed line represents $\left(F / F_{0}\right)$ of 1 , corresponding to preneomycin baseline levels. (B) Mean cross-correlation of transformed fluorescence intensity values of HyPer relative to mitoRGECO events occurring within the same cell. Maximal cross-correlation value (R) was at -1 minute $(r=0.411, P=0.013)$, indicating that the initial onset of increased mitoRGECO fluorescence (mitochondrial $\mathrm{Ca}^{2+}$ uptake) precedes HyPer by 1 minute. Error bars $= \pm 1$ SEM; $n=36$ cells from 1 to 3 neuromasts per animal and 7 animals. pared with controls $(P<0.001$ for both; Figure $7 \mathrm{~B})$. TEMPOL did not alter cellROX fluorescence, but reduced mitoSOX fluorescence by $14 \%$ when compared with CsA alone $(P<0.01$; Figure $7 \mathrm{~B})$. MitoTEMPO, on the other hand, reduced both cellROX and mitoSOX fluorescence by $30 \%$ and $45 \%$, respectively, when compared with CsA alone $(P<0.001$ for both; Figure 7B). These results indicate that in hair cells mitoTEMPO is more effective at reducing mitochondria-specific oxidative changes than TEMPOL.

We next asked whether the differential localization of these electron sinks alters aminoglycoside toxicity. TEMPOL had no discernible effect on hair cell number across a range of neomycin concentrations, while mitoTEMPO protected hair cells $(P<0.0001 ;$ Figure 7C). We observed that cellROX fluorescence in dying cells treated with TEMPOL resembled that of dying cells not exposed to ROS sinks, while mitoTEMPO substantially reduced any changes in cellROX fluorescence $(P<0.001$; Figure 7D).

We next wished to determine whether the protection we observed could be explained by the targeting of mitoTEMPO to mitochondria. To address this, we coincubated hair cells with CsA and mitoTEMPO to determine the combinatorial effect on aminoglycoside-induced oxidation and subsequent toxicity. Consistent with our previous studies (36), pretreatment with CsA sensitizes hair cells to the toxic effects of aminoglycosides by exacerbating accumulation of $\mathrm{Ca}^{2+}$ in mitochondria, increasing hair cell death by approximately $30 \%$ across multiple neomycin concentrations $(P<0.0001$; Figure 7E). Cotreatment with mitoTEMPO reduced the sensitizing effects of CsA on neomycin exposure $(P<0.0001$; Figure $7 \mathrm{E}$ ). To determine whether this sensitization could be explained by elevated ROS, we monitored the effects of CsA on HyPer fluorescence in dying hair cells exposed to neomycin (Figure 7F). HyPer fluorescence was increased within dying hair cells treated with both neomycin and CsA, with maximal levels approximately $300 \%$ higher than in dying cells treated with neomycin alone (Figure 7F). After inclusion of mitoTEMPO, HyPer fluorescence of dying cells treated with CsA and neomycin was similar to that observed in dying cells exposed to neomycin alone (Figure 7F). Together our results suggest that oxidative changes within mitochondria are a key component of aminoglycoside-induced hair cell death.

\section{Discussion}

Mitochondria are thought of as the primary generators of ROS within most cell types, since they act as the core of a cell's energy production through OXPHOS $(23,46)$. As such they are heavily implicated as the source of ROS during aminoglycoside-induced hair cell death. We demonstrate here that mitochondrial oxidation occurs within hair cells following aminoglycoside exposure in a manner that is predictive of cell death. Such changes strongly correlate with both the intensity and the timing of cytoplasmic ROS detection, suggesting that mitochondria are a major source of ROS during this event.

Mitochondrial $\mathrm{Ca}^{2+}$ as a contributor to ROS during aminoglycoside-induced hair cell death. Within mitochondria, $\mathrm{Ca}^{2+}$ uptake, transmembrane potential, and ROS generation are extensively interrelated $(33,38,47)$. Mitochondrial $\mathrm{Ca}^{2+}$ can stimulate OXPHOS, promoting ROS generation from respiratory complexes I and III. This also leads to an increase in $\Delta \psi$ as protons accumulate within intermembrane space, and can promote additional $\mathrm{Ca}^{2+}$ uptake through the voltage-dependent anion channel (VDAC) (48-50). Relatively high $\Delta \psi$ is often associated with elevated mitochondrial ROS production $(51,52)$, and reduction of $\Delta \psi$ can reduce cellular ROS levels under conditions of cell stress (53). Thus, it is critical
Figure 6. Pharmacological inhibition of mitochondrial $\mathrm{Ca}^{2+}$ uptake reduces overall change in oxidative state of hair cells exposed to aminoglycosides. (A-C) Maximal transformed $\left(F / F_{0}\right)$ fluorescence intensity of cellROX (A), mitoSOX (B), and HyPer (C) in cells following exposure to $50 \mu \mathrm{M}$ neomycin and the mitochondrial uniporter inhibitor Ru360. Data shown are only for dying cells. Hair cells were first loaded with the indicated dye (if applicable) for 30 minutes, followed by 30 -minute exposure to Ru360. They were then mounted on the microscope stage for imaging and exposed to Ru360 and/or neomycin, while fluorescence readings were recorded. Horizontal lines and error bars represent mean \pm 1 SEM (A-C) Student's $t$ test, Welch's correction; ${ }^{*} P<0.05,{ }^{* *} P<0.01$; $n=10$ (A, neomycin alone) 16 (A, neomycin + Ru360), 11 (B, neomycin alone), 10 (B, neomycin + Ru360), 8 (C, neomycin alone), and 3 (C, neomycin + Ru360) neuromasts.
A

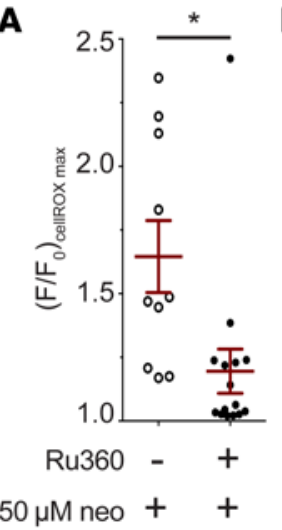

B

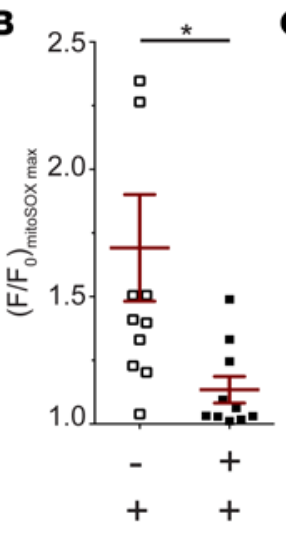

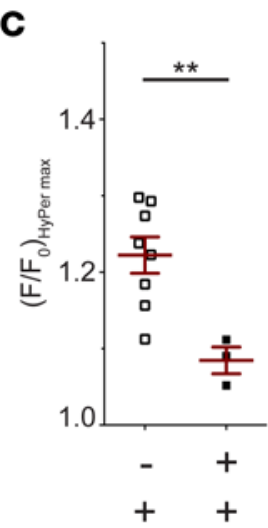


A

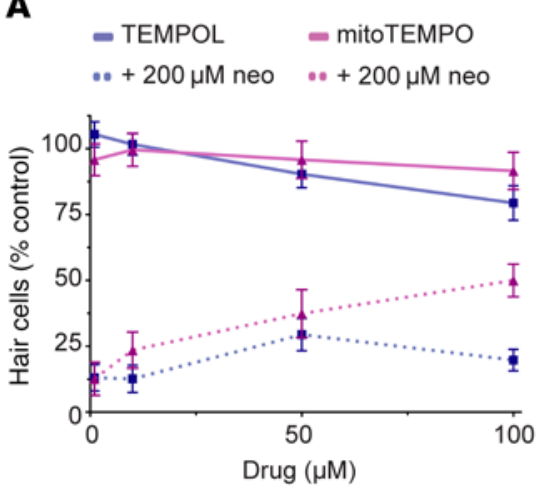

B

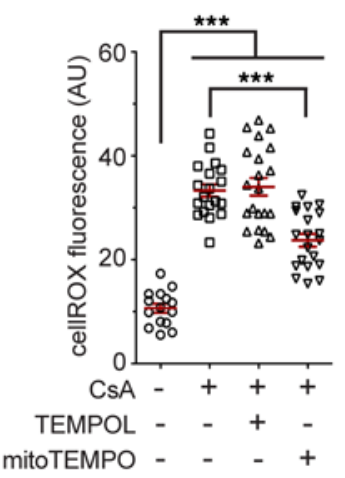

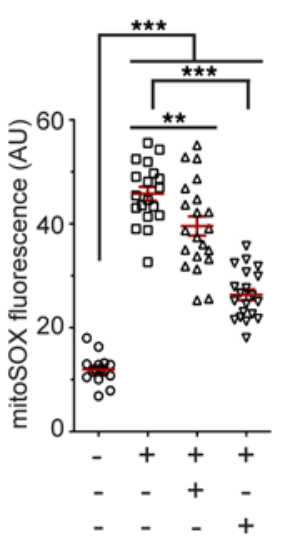

C

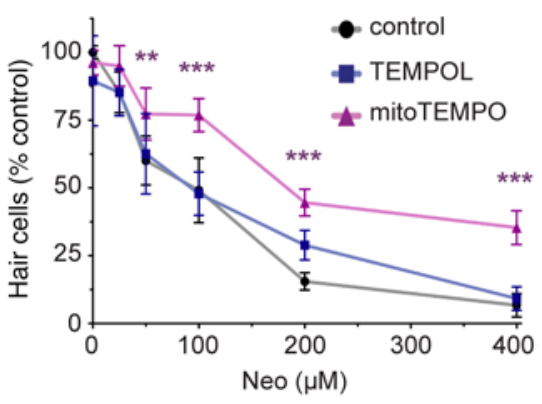

D

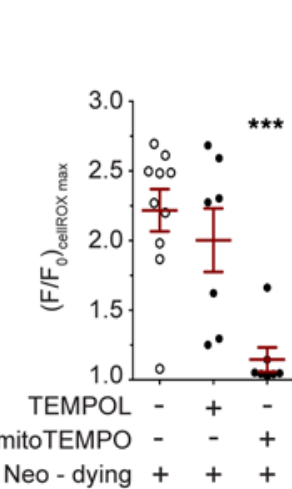

E

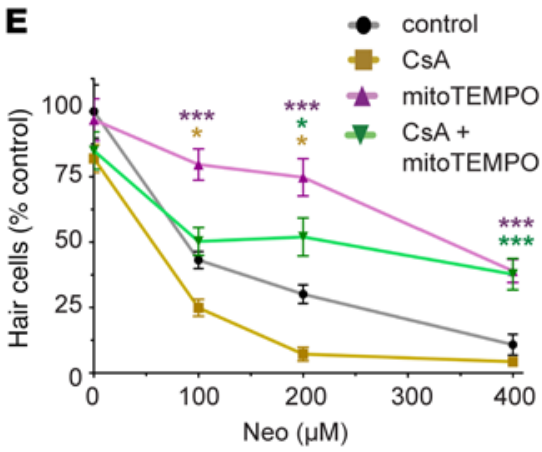

$\mathbf{F}$

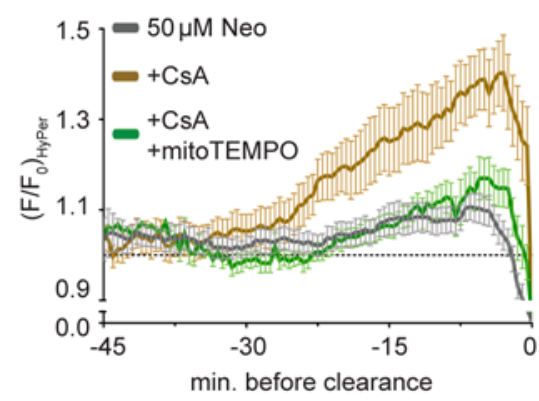

Figure 7. Mitochondrial-targeted electron sinks reduce mitochondrial and cytoplasmic oxidation following aminoglycoside exposure, and mitigate aminoglycoside toxicity. (A) Concentrations of TEMPOL and mitoTEMPO were determined by administration of either drug alone (solid lines) or with $200 \mu \mathrm{M}$ neomycin (dashed lines). For subsequent experiments, cells were preincubated with $50 \mu \mathrm{M}$ TEMPOL or mitoTEMPO for 30 minutes before neomycin exposure. $n=5$ neuromasts from 5 animals per group. (B) Fluorescence intensity of cellROX or mitoSOX following pretreatment with TEMPOL or mitoTEMPO and coexposure to CSA. Hair cells were first loaded with indicator dye, then pretreated 30 minutes with TEMPOL or mitoTEMPO, followed by coexposure to CsA. One-way ANOVA, Tukey post-test. $n=15$ (control), 19 (CsA), 21 (CsA + TEMPOL), and 20 (CsA + mitoTEMPO) neuromasts from 3 to 5 animals per group. (C) Effects of TEMPOL or mitoTEMPO pretreatment on hair cell number following neomycin exposure. $n=5$ neuromasts from 5 animals per group from 2 experiments. (D) Maximal cellROX fluorescence change in dying cells after $50 \mu M$ neomycin exposure. $n=10$ (neomycin), 7 (neomycin + TEMPOL), and 7 (neomycin + mitoTEMPO), from 3 animals per group. (E) Effects of mitoTEMPO cotreatment with CsA on hair cell number following neomycin exposure. $n=5$ neuromasts from 5 animals per group. (F) Mean transformed $\left(F / F_{0}\right)$ HyPer intensity data in dying hair cells first exposed to mitoTEMPO, or CsA and mitoTEMPO, and then exposed to $50 \mu \mathrm{M}$ neomycin. Fluorescence data were aligned to the point of cell clearance from the neuromast. The dashed bar represents $\left(F / F_{0}\right)$ of 1 , corresponding to preneomycin baseline levels. $n=39$ (50 $\mu \mathrm{M}$ neomycin, dying), 20 (CsA), and 11 (CsA + mitoTEMPO) cells from 1 to 3 neuromasts per animal. Two-way ANOVA in C and $\mathbf{E}$, Tukey post-test. In D, 1-way ANOVA, Holm- Šidák post-test. In all instances, error bars $=$ SEM; ${ }^{*} P<0.05,{ }^{* *} P<0.01,{ }^{* * *} P<0.001$.

that OXPHOS intermediates are rapidly detoxified or otherwise removed from mitochondrial space. This is handled by the mitochondrial transition pore, which removes metabolites such as $\mathrm{Ca}^{2+}$ that increase $\Delta \psi(54,55)$.

There is ample evidence to suggest that mitochondrial dysfunction occurs during aminoglycoside-induced hair cell death. Several laboratories, including ours, have noted swollen mitochondria in hair cells exposed to aminoglycosides (56-61). This type of morphology is consistent with mitochondrial $\mathrm{Ca}^{2+}$ overload $(35,62)$, and we have previously shown that mitochondrial $\mathrm{Ca}^{2+}$-driven increases in $\Delta \psi$ are both a necessary and a sufficient component of aminoglycoside-induced hair cell death (36). Here we show that a functional consequence of this event is the oxidation of mitochondria and production of ROS. These findings are in general agreement with those of Chen et al. (2013), who demonstrated the important role of the mitochon- drial $\mathrm{O}_{2}^{--}$scavenger peroxiredoxin 3; when rendered inactive, intracellular ROS levels are elevated and murine cochlear hair cells are sensitized to aminoglycoside toxicity (63).

While many pathways from distinct cellular compartments intersect to govern redox homeostasis (64), our data suggest that mitochondria are perhaps the largest contributor to the oxidative changes observed during aminoglycoside-induced hair cell death. Modulation of mitochondrial $\mathrm{Ca}^{2+}$ uptake or release alters oxidation within hair cells exposed to aminoglycosides in a manner consistent with their central involvement in the process. Furthermore, aminoglycoside protection afforded by mitoTEMPO lies in stark contrast to that of TEMPOL despite the ability of both compounds to act as electron sinks (65-67).

It is likely that other sources of ROS (or also reactive nitrogen species) within the cell contribute to aminoglycoside toxicity. Work in various eukaryotic systems has shown that aminoglyco- 
sides are capable of forming complexes with membrane lipids (68-72) and free iron (73). Ternary complexes between these molecules are capable of propagating highly reactive ROS and reactive nitrogen species from $\mathrm{H}_{2} \mathrm{O}_{2}(74,75)$. Such observations are not necessarily incompatible with the notion that mitochondria are centrally involved in the process of ROS generation, as $\mathrm{O}_{2}{ }^{--}$production generates an increase in free iron within mitochondria $(76,77)$ that can be inhibited with mitoTEMPO $(78)$.

It is worth noting that ruthenium red has been reported as an inhibitor of the hair cell mechanotransduction channel (79). As an analog for ruthenium red, it is possible that the effects observed with Ru360 treatment are due to mechanotransduction channel inhibition and blockade of aminoglycoside entry into the cell. However, as there is a clear mitochondrial component to aminoglycoside-induced toxicity, we are inclined to argue that alteration of mitochondrial ROS levels we observe with Ru360 treatment is due to a direct effect of its inhibition of the mitochondrial uniporter.

Drawing parallels with prokaryotic toxicity. Several recent studies have suggested that antibiotics induce bacterial metabolic shifts following interaction with their target. In the case of aminoglycosides these events occur after direct interaction with rRNA, stimulating bacterial respiration (80). Expression of genes involved in metabolism and respiration is upregulated in the presence of aminoglycosides, and metabolic rates appear to increase $(20,81)$. Increased respiration byproducts may therefore be central to the bacterial killing ability of aminoglycosides; indeed, decreased oxygen availability can dampen bactericidal efficiency (82). Furthermore, modulation of antioxidant response pathways also affects antibiotic efficacy. This suggests that increased metabolic activity through the citric acid cycle is a primary source of ROS during bacterial cell death downstream of their interaction with rRNA, and seems to parallel events underlying aminoglycoside toxicity observed in eukaryotic cells.

So then, do the underlying mechanisms of bacterial toxicity prevent selective killing of prokaryotic cells over hair cells when administered systemically? At first glance, it would appear so, as the secondary structure of rRNA through which they directly bind is similar in cytoplasmic and mitochondrial ribosomes of eukaryotes (83). However, recent data suggest that some mitochondrial dysfunction seen during ototoxicity may be due to off-target interactions with mitochondrial rRNA that have no bearing on bactericidal efficacy. For example, Agris and colleagues have identified rRNA loops to which aminoglycosides bind strongly in mitochondria but not in prokaryotes (84). While this remains to be thoroughly evaluated, aminoglycosides engineered for increased selectivity of prokaryotic rRNA (85) offer the expectation of reduced mitochondrial dysfunction and subsequent ROS generation within hair cells.

Therapeutic prevention of mitochondrial ROS. The behavior of cytoplasmic redox indicators in hair cells surviving neomycin exposure indicates that moderate increases in cytoplasmic ROS are not necessarily toxic to hair cells. This observation contrasts with the more robust separation of mitoSOX behavior between living and dying cells. It suggests that a mode of action for proposed antioxidant therapies for attenuation of aminoglycoside toxicity $(3,86$, 87) lies within mitochondria, not in other compartments. Compounds championed by these studies, such as reduced glutathione, $N$-acetylcysteine, ubiquinone, and vitamin $\mathrm{E}$, are known to be found at high levels within mitochondria and used there to main- tain an appropriate redox balance (88-91); exogenous supplementation may boost their already high levels within mitochondria.

This work suggests that strategies directed at limiting mitochondrial ROS production may be of therapeutic value to patients taking large and/or prolonged courses of aminoglycoside antibiotics. However, it is noteworthy that hair cell protection is incomplete in our zebrafish model, even when large increases in oxidation are inhibited. This may be due to specific sites or species of ROS generation that are particularly toxic to the cell, or other pleiotropic effects of aminoglycosides on cell death pathways (92). It is important to emphasize the variety of ROS species can be generated at multiple sites within mitochondria. Furthermore, there exist substantial and complex cellular networks tasked with maintaining redox homeostasis. In addition, from the studies described here and from our previous studies (36) it appears that dysregulations of $\mathrm{Ca}^{2+}$ are largely responsible for the ROS accumulation and subsequent hair cell death. Linking mitochondrial $\mathrm{Ca}^{2+}$ uptake to mitochondrial dysfunction and ROS generation within dying hair cells exposed to aminoglycosides is an important step forward, as specifically targeting $\mathrm{Ca}^{2+}$ uptake and mitochondrial ROS generation may be a more effective strategy than generalized antioxidant therapies.

\section{Methods}

Fish. Experiments were carried out on zebrafish larvae 5-7 days after fertilization in E3 embryo medium (14.97 mM NaCl, $500 \mu \mathrm{M} \mathrm{KCl}, 42$ $\mu \mathrm{M} \mathrm{Na}_{2} \mathrm{HPO}_{4}, 150 \mu \mathrm{M} \mathrm{KH}_{2} \mathrm{PO}_{4}, 1 \mathrm{mM} \mathrm{CaCl}$ dehydrate, $1 \mathrm{mM} \mathrm{MgSO}_{4}$, $0.714 \mathrm{mM} \mathrm{NaHCO}_{3}, \mathrm{pH} 7.2$ ) at $28.5^{\circ} \mathrm{C}$, unless otherwise indicated. All animals were of the $\mathrm{AB}$ strain. Larvae were used before the stage at which sex is determined in zebrafish.

Transgenesis. The transgenic line $\mathrm{Tg}$ (atoh1a:tdTomato) has been described (93), and was provided as a gift from Cecilia Moens (Fred Hutchinson Cancer Research Center, Seattle, Washington, USA). The genetically encoded $\mathrm{H}_{2} \mathrm{O}_{2}$ indicator HyPer (34) was cloned using the Gateway system (Invitrogen) to generate constructs under control of the hair cell-specific myosin $6 b$ promoter (94). $\mathrm{Tg}[\text { myo6b:HyPer }]^{\mathrm{w} 120}$ was maintained as a transgenic line. The transgenic construct driving hair cell-specific expression of mitochondrial-targeted RGECO (mitoRGECO; [myo6b:mitoRGECO]) has been previously described (36). Supplemental Table 1 further describes the nature of these indicators.

Indicator dyes. To detect changes in mitochondrial transmembrane potential, zebrafish were incubated at $28.5^{\circ} \mathrm{C}$ in $10 \mathrm{nM}$ tetramethyl rhodamine ester (TMRE; dissolved in DMSO; Thermo Fisher) in E3 medium. To detect redox changes, zebrafish were incubated at $28.5^{\circ} \mathrm{C}$ in $1 \mu \mathrm{M}$ mitoSOX or $2 \mu \mathrm{M}$ cellROX (both dissolved in DMSO; Thermo Fisher) in E3 medium. Incubation times varied between 30 and 90 minutes, as we observed lot-to-lot variation in loading/labeling times. After loading, zebrafish were washed once in E3 media, and subjected to imaging as described below. Supplemental Table 1 further describes the nature of these indicators.

Compound treatment. Neomycin (Sigma-Aldrich) was used at indicated concentrations in embryo media. For all experiments, animals were exposed to aminoglycoside for 30 minutes for hair cell survival analyses at $28.5^{\circ} \mathrm{C}$, or for the amount of time indicated during imaging (typically 60 minutes). We have previously demonstrated the ability of Ru360 (500 $\mathrm{nM}$ final concentration in water; Tocris Biosciences) and CsA (200 nM final concentration as SandImmune; Novartis) to modulate mitochondri$\mathrm{al} \mathrm{Ca}^{2+}$ as well as hair cell survival in the presence of neomycin (36). 
To evaluate the response of cellROX, xanthine oxidase (Cayman Chemical) was dissolved to $0.1 \mathrm{U} / \mathrm{ml}$ in embryo media with MS-222 for imaging. A $5 \times$ solution of $2.5 \mu \mathrm{M}$ xanthine (Sigma-Aldrich) was added to the imaging chamber following the baseline period. Imaging was performed as described below.

In the comparison of ROS scavengers, the concentration of mitochondrial-targeted mitoTEMPO that was sufficient to protect approximately $50 \%$ of lateral line hair cells from $200 \mu \mathrm{M}$ neomycin exposure was first determined ( $50 \mu \mathrm{M}$; Figure $7 \mathrm{~A})$. This concentration was then used in experiments in the comparison of TEMPOL and mitoTEMPO. At these concentrations, both compounds were capable of reducing fluorescence of ROS indicator dyes following exposure to both CsA and neomycin (Figure 7, B and D).

To evaluate the effectiveness of ROS scavengers on mitochondrial oxidation, larvae were first incubated in cellROX and mitoSOX alone or in combination with scavenger for 30 minutes, then exposed to CsA alone or in combination with scavenger for 60 minutes. Larvae were then anesthetized, mounted, and imaged as described below.

Hair cell counts. Animals were pretreated in ROS modulators for 30 minutes, followed by coadministration with the specified concentration of neomycin for 30 minutes. They were then washed 3 times in E3 and allowed to recover for 30 minutes. Hair cells were then either detected using the vital dye Yo-Pro ( $2 \mu \mathrm{M}$ in DMSO; Thermo Fisher) with additional washout (28), or fixed with $4 \%$ paraformaldehyde and subjected to antibody labeling with anti-parvalbumin antisera (MAB1572; Millipore) (95). Mean hair cell counts across 6 neuromasts (IO4, M2, MI1, O1, O2, OC1; ref. 96) were calculated from at least 5 animals. Control E3 contained 0.2\% DMSO.

Imaging and analysis. Imaging and analysis were performed as previously described (30). Briefly, 5-7 days after fertilization, zebrafish were immersed in E3 containing 0.2\% MESAB (MS-222; ethyl-3-aminobenzoate methanesulfonate) and stabilized using a slice anchor harp (Harvard Instruments) so that neuromasts on immobilized animals had free access to surrounding media. We chose neuromasts that were positioned parallel to our imaging cover glass as this type of positioning allows us to visualize behavior of most of the cells within the neuromast, as well as visualize changes that might be restricted to apical or basolateral regions of the cell. Because each fish is mounted differently, we were unable to restrict our imaging to particular neuromasts. We imaged both anterior and posterior lateral line neuromasts in our analyses. Imaging was performed at ambient temperature, typically $24^{\circ} \mathrm{C}$ to $25^{\circ} \mathrm{C}$. Baseline fluorescence readings were taken prior to aminoglycoside exposure in 30-second intervals for 2.5 minutes. Aminoglycoside then was added as a $4 \times$ concentrated stock to achieve the final indicated concentration, and fluorescence intensity readings were acquired in 30-second intervals for 60 minutes. A motorized stage with set $x, y$, and $z$ coordinates enabled acquisition from multiple neuromasts per fish during each imaging session. Camera intensification was set to keep exposure times less than $50 \mathrm{~ms}$ for mitoGCaMP; $150 \mathrm{~ms}$ for HyPer, cellROX, or mitoRGECO; and $350 \mathrm{~ms}$ for TMRE or mitoSOX, while keeping baseline pixel intensity less than $25 \%$ of saturation. Camera gain was set at maximum to minimize photobleaching. $Z$ axis optical sections were taken at $2-\mu \mathrm{m}$ intervals through the depth of the neuromast, typically $12 \mu \mathrm{m}$. HyPer and cellROX fluorescence was acquired with a 488-nm laser and 535/30 emission filter. TMRE and RGECO fluorescence was acquired with a 561-nm laser and $617 / 73$ emission filter, while mitoSOX fluorescence was acquired with a 488-nm laser and 617/73 emission filter. Controls were performed to ensure that cross-talk between indicators was less than $5 \%$ of signal when multiple channels were captured for an experiment.

Time-lapse images were aligned using either ImageJ (NIH) or 3i SlideBook software. Fluorescence data were extracted by drawing of regions of interest around individual cells, where mean fluorescence intensity within the area of the region of interest was exported for analyses. Fluorescence intensities were calculated relative to the mean baseline intensity of each individual hair cell before aminoglycoside exposure. Cells were categorized as living or dying based on their fragmentation and clearance from the neuromast following 60 minutes of aminoglycoside exposure. Clearance is a hallmark of hair cell death in the lateral line, and provides a binary means to define a hair cell as "surviving" or "dying" when used in conjunction with time-lapse imaging. The use of clearance as an endpoint is supported by previous studies: (a) Hair cell "corpses" are not present in neuromasts exposed to aminoglycosides, suggesting that hair cells present in a neuromast are "alive." In support of this we have previously reported that calcium dynamics continue to change in dying cells up until the point of cell clearance (30), and that cell membranes remain intact until minutes before cell clearance (31). (b) Early work from our group has shown that virtually all of the lateral line hair cell death in unanesthetized, free-swimming larvae occurs within an hour following neomycin exposure (27). We have compared the dose-response curves of unanesthetized, free-swimming larvae with those of larvae anesthetized and mounted for imaging and find the 2 are not statistically different (not shown). We therefore feel confident that we are not erroneously categorizing cells based on events that occur outside of our imaging window.

For analysis, living and dying cells were chosen randomly at the end of each time lapse. For imaging during mitochondrial $\mathrm{Ca}^{2+}$ or ROS modulation, animals were exposed to modulators 30 minutes prior to recording of baseline fluorescence and coadministered with neomycin at the indicated concentrations.

For each treatment condition, at least 3 replications were performed on different days, and fluorescence intensities of no more than 5 cells per neuromast and 3 neuromasts per animal were used in analyses. Our analyses indicate that individual cells from the same neuromast were prone to a mild-to-moderate intra-clustering bias that was eliminated by calculation of the mean fluorescence intensity of cells within a neuromast before performance of group-wise comparisons. This type of approach is an appropriate correction for potential intra-clustering biases (97-99). Supplemental Figure 1 illustrates maximal fluorescence intensity of cells expressing the biosensor HyPer compared across several grouping methods: cells within a neuromast, neuromasts within an animal, and cells across animals. Note that when mean neuromast values are presented, intra-clustering correlation (ICC) scores approach 0 , indicating very little ICC bias, and these scores are actually lower than that of individual cells compared across animals. Individual cells were used to calculate timing events between pairwise indicators.

Statistics. GraphPad Prism 5.0 software was used for all statistical analyses except ICC calculations and cross-correlations. Overall analyses and post hoc tests are indicated in figure legends. Student's $t$ test was performed as 2-tailed. ICC values were calculated according to ref. 98 using data from 1-way ANOVAs performed in Prism, and cross-correlation analyses were performed in Microsoft Excel. A P value less than 0.05 was considered significant. 
Study approval. All experiments were approved by the University of Washington Institution Animal Care and Use Committee.

\section{Author contributions}

RE, HCO, EWR, and DWR designed the studies. RE, SBP, TL, and PW conducted experiments. RE, SBP, HCO, EWR, and DWR analyzed data and wrote the manuscript.

\section{Acknowledgments}

The authors thank David White for fish care, and Dale Hailey and Tamara Stawicki for sharing of unpublished data. This work was supported by National Institute on Deafness and Other Communication Disorders grants DC05987 and DC04661, and Ruth Kirschstein National Research Service Award fellowship DC012244.

Address correspondence to: Edwin W. Rubel, Virginia Merrill Bloedel Hearing Research Center, Box 357923, University of Washington, Seattle, Washington 98195, USA. Phone: 206.543.8360; E-mail: rubel@uw.edu. Or to: David W. Raible, Department of Biological Structure, Box 357420, University of Washington, Seattle, Washington 98195-7420, USA. Phone: 206.616.1048; E-mail: draible@uw.edu.
1. Jackson J, Chen C, Buising K. Aminoglycosides: how should we use them in the 21st century? Curr Opin Infect Dis. 2013;26(6):516-525.

2. Poulikakos P, Falagas ME. Aminoglycoside therapy in infectious diseases. Expert Opin Pharmacother. 2013;14(12):1585-1597.

3. Huth ME, Ricci AJ, Cheng AG. Mechanisms of aminoglycoside ototoxicity and targets of hair cell protection. Int JOtolaryngol. 2011;2011:937861.

4. Böttger EC, Schacht J. The mitochondrion: a perpetrator of acquired hearing loss. Hear Res. 2013;303:12-19.

5. Warchol ME. Cellular mechanisms of aminoglycoside ototoxicity. Curr Opin Otolaryngol Head Neck Surg. 2010;18(5):454-458.

6. Hirose K, Hockenbery DM, Rubel EW. Reactive oxygen species in chick hair cells after gentamicin exposure in vitro. Hear Res. 1997;104(1-2):1-14.

7. Clerici WJ, Hensley K, DiMartino DL, Butterfield DA. Direct detection of ototoxicant-induced reactive oxygen species generation in cochlear explants. Hear Res. 1996;98(1-2):116-124.

8. Jiang $\mathrm{H}$, Sha SH, Schacht J. NF- $\kappa B$ pathway protects cochlear hair cells from aminoglycoside-induced ototoxicity. J Neurosci Res. 2005;79(5):644-651.

9. Hong SH, et al. Gentamicin induced nitric oxiderelated oxidative damages on vestibular afferents in the guinea pig. Hear Res. 2006;211(1-2):46-53.

10. Jiang H, Sha SH, Schacht J. Rac/Rho pathway regulates actin depolymerization induced by aminoglycoside antibiotics. JNeurosci Res. 2006;83(8):1544-1551.

11. Choung YH, Taura A, Pak K, Choi SJ, Masuda M, Ryan AF. Generation of highly-reactive oxygen species is closely related to hair cell damage in rat organ of Corti treated with gentamicin. Neuroscience. 2009;161(1):214-226.

12. Sha SH, Taylor R, Forge A, Schacht J. Differential vulnerability of basal and apical hair cells is based on intrinsic susceptibility to free radicals. Hear Res. 2001;155(1-2):1-8.

13. Song BB, Sha SH, Schacht J. Iron chelators protect from aminoglycoside-induced cochleoand vestibulo-toxicity. Free Radic Biol Med. 1998;25(2):189-195.

14. Song BB, Schacht J. Variable efficacy of radical scavengers and iron chelators to attenuate gentamicin ototoxicity in guinea pig in vivo. Hear Res. 1996;94(1-2):87-93.

15. Kawamoto K, et al. Antioxidant gene therapy can protect hearing and hair cells from ototoxicity.
Mol Ther. 2004;9(2):173-181.

16. Fetoni AR, Sergi B, Scarano E, Paludetti G, Ferraresi A, Troiani D. Protective effects of $\alpha$-tocopherol against gentamicin-induced Oto-vestibulo toxicity: an experimental study. Acta Otolaryngol. 2003;123(2):192-197.

17. Sha SH, Schacht J. Antioxidants attenuate gentamicin-induced free radical formation in vitro and ototoxicity in vivo: $\mathrm{D}$-methionine is a potentia protectant. Hear Res. 2000;142(1-2):34-40.

18. Takumida M, Popa R, Anniko M. Free radicals in the guinea pig inner ear following gentamicin exposure. ORL J Otorhinolaryngol Relat Spec. 1999;61(2):63-70.

19. Kohanski MA, Dwyer DJ, Hayete B, Lawrence CA, Collins JJ. A common mechanism of cellular death induced by bactericidal antibiotics. Cell. 2007;130(5):797-810.

20. Kohanski MA, Dwyer DJ, Wierzbowski J, Cottarel G, Collins JJ. Mistranslation of membrane proteins and two-component system activation trigger antibiotic-mediated cell death. Cell. 2008;135(4):679-690.

21. Kalghatgi S, et al. Bactericidal antibiotics induce mitochondrial dysfunction and oxidative damage in Mammalian cells. Sci Transl Med. 2013;5(192):192ra85.

22. Kushnareva Y, Newmeyer DD. Bioenergetics and cell death. Ann N Y Acad Sci. 2010;1201:50-57.

23. Balaban RS, Nemoto S, Finkel T. Mitochondria, oxidants, and aging. Cell. 2005;120(4):483-495.

24. Rizzuto R, et al. $\mathrm{Ca}(2+)$ transfer from the ER to mitochondria: when, how and why. Biochim Biophys Acta. 2009;1787(11):1342-1351.

25. Loschen G, Azzi A, Richter C, Flohé L. Superoxide radicals as precursors of mitochondrial hydrogen peroxide. FEBS Lett. 1974;42(1):68-72.

26. Boveris A, Chance B. The mitochondrial generation of hydrogen peroxide. General properties and effect of hyperbaric oxygen. Biochem J. 1973;134(3):707-716.

27. Harris JA, Cheng AG, Cunningham LL, MacDonald G, Raible DW, Rubel EW. Neomycin-induced hair cell death and rapid regeneration in the lateral line of zebrafish (Danio rerio). JAssoc Res Otolaryngol. 2003;4(2):219-234.

28. Santos F, MacDonald G, Rubel EW, Raible DW. Lateral line hair cell maturation is a determinant of aminoglycoside susceptibility in zebrafish (Danio rerio). Hear Res. 2006;213(1-2):25-33.

29. Esterberg R, Coffin AB, Ou H, Simon JA, Raible DW, Rubel EW. Fish in a dish drug discovery for hearing habilitation. Drug Discov Today Dis Models. 2013;10(1):10.1016/j.ddmod.2012.02.001.

30. Esterberg R, Hailey DW, Coffin AB, Raible DW, Rubel EW. Disruption of intracellular calcium regulation is integral to aminoglycoside-induced hair cell death. J Neurosci. 2013;33(17):7513-7525.

31. Esterberg R, Hailey DW, Rubel EW, Raible DW. ER-mitochondrial calcium flow underlies vulnerability of mechanosensory hair cells to damage. JNeurosci. 2014;34(29):9703-9719.

32. Manning AS, Coltart DJ, Hearse DJ. Ischemia and reperfusion-induced arrhythmias in the rat. Effects of xanthine oxidase inhibition with allopurinol. Circ Res. 1984;55(4):545-548.

33. Brookes PS, Yoon Y, Robotham JL, Anders MW, Sheu SS. Calcium, ATP, and ROS: a mitochondrial love-hate triangle. Am J Physiol Cell Physiol. 2004;287(4):C817-C833.

34. Belousov VV, et al. Genetically encoded fluorescent indicator for intracellular hydrogen peroxide. Nat Methods. 2006;3(4):281-286.

35. Giorgi C, et al. Mitochondrial $\mathrm{Ca}(2+)$ and apoptosis. Cell Calcium. 2012;52(1):36-43.

36. Esterberg R, Hailey DW, Rubel EW, Raible DW. ER-mitochondrial calcium flow underlies vulnerability of mechanosensory hair cells to damage. JNeurosci. 2014;34(29):9703-9719.

37. Mukhopadhyay P, Rajesh M, Haskó G, Hawkins BJ, Madesh M, Pacher P. Simultaneous detection of apoptosis and mitochondrial superoxide production in live cells by flow cytometry and confocal microscopy. Nat Protoc. 2007;2(9):2295-2301.

38. Adam-Vizi V, Starkov AA. Calcium and mitochondrial reactive oxygen species generation: how to read the facts. JAlzheimers Dis. 2010;20(suppl 2):S413-S426.

39. Peng TI, Jou MJ. Oxidative stress caused by mitochondrial calcium overload. Ann N Y Acad Sci. 2010;1201:183-188.

40. Zhao Y, et al. An expanded palette of genetically encoded $\mathrm{Ca}^{2+}$ indicators. Science. 2011;333(6051):1888-1891.

41. Matlib MA, et al. Oxygen-bridged dinuclear ruthenium amine complex specifically inhibits $\mathrm{Ca}^{2+}$ uptake into mitochondria in vitro and in situ in single cardiac myocytes. J Biol Chem. 1998;273(17):10223-10231.

42. Liang HL, Arsenault J, Mortensen J, Park F, Johnson CP, Nilakantan V. Partial attenuation of cytotoxicity and apoptosis by SOD1 in ischemic renal epithelial cells. Apoptosis. 2009;14(10):1176-1189.

43. Dikalova AE, et al. Therapeutic targeting of mitochondrial superoxide in hypertension. Circ Res. 2010;107(1):106-116. 
44. Smith RA, Porteous CM, Gane AM, Murphy MP. Delivery of bioactive molecules to mitochondria in vivo. Proc Natl Acad Sci U S A. 2003;100(9):5407-5412.

45. Halestrap AP, Connern CP, Griffiths EJ, Kerr PM. Cyclosporin A binding to mitochondrial cyclophilin inhibits the permeability transition pore and protects hearts from ischaemia/reperfusion injury. Mol Cell Biochem. 1997;174(1-2):167-172.

46. Liu Y, Fiskum G, Schubert D. Generation of reactive oxygen species by the mitochondrial electron transport chain. JNeurochem. 2002;80(5):780-787.

47. Feissner RF, Skalska J, Gaum WE, Sheu SS. Crosstalk signaling between mitochondrial $\mathrm{Ca}^{2+}$ and ROS. Front Biosci (LandmarkEd). 2009;14:1197-1218.

48. Kirichok Y, Krapivinsky G, Clapham DE. The mitochondrial calcium uniporter is a highly selective ion channel. Nature. 2004;427(6972):360-364.

49. Nguyen KT, García-Chacón LE, Barrett JN, Barrett EF, David G. The Psi(m) depolarization that accompanies mitochondrial $\mathrm{Ca}^{2+}$ uptake is greater in mutant SOD1 than in wild-type mouse motor terminals. Proc Natl Acad Sci U S A. 2009;106(6):2007-2011.

50. Nicholls DG, Chalmers S. The integration of mitochondrial calcium transport and storage. J Bioenerg Biomembr. 2004;36(4):277-281.

51. Marchi S, et al. Mitochondria-ros crosstalk in the control of cell death and aging. J Signal Transduct. 2012;2012:329635.

52. Suski JM, Lebiedzinska M, Bonora M, Pinton P, Duszynski J, Wieckowski MR. Relation between mitochondrial membrane potential and ROS formation. Methods Mol Biol. 2012;810:183-205.

53. Starkov AA, Fiskum G. Regulation of brain mitochondrial $\mathrm{H} 2 \mathrm{O} 2$ production by membrane potential and $\mathrm{NAD}(\mathrm{P}) \mathrm{H}$ redox state. J Neurochem. 2003;86(5):1101-1107.

54. Ichas F, Jouaville LS, Mazat JP. Mitochondria are excitable organelles capable of generating and conveying electrical and calcium signals. Cell. 1997;89(7):1145-1153.

55. Pinton $\mathrm{P}$, et al. Protein kinase $\mathrm{C}$ beta and prolyl isomerase 1 regulate mitochondrial effects of the life-span determinant p66Shc. Science. 2007;315(5812):659-663.

56. Owens KN, Cunningham DE, MacDonald G, Rubel EW, Raible DW, Pujol R. Ultrastructural analysis of aminoglycoside-induced hair cell death in the zebrafish lateral line reveals an early mitochondrial response. JComp Neurol. 2007;502(4):522-543.

57. Fermin CD, Igarashi M. Aminoglycoside ototoxicity in the chick (Gallus domesticus) inner ear: I. The effects of kanamycin and netilmicin on the basilar papilla. Am JOtolaryngol.1983;4(3):174-183.

58. Mangiardi DA, McLaughlin-Williamson K, May KE, Messana EP, Mountain DC, Cotanche DA. Progression of hair cell ejection and molecular markers of apoptosis in the avian cochlea following gentamicin treatment. J Comp Neurol. 2004;475(1):1-18

59. Dehne N, Rauen U, de Groot H, Lautermann J. Involvement of the mitochondrial permeability transition in gentamicin ototoxicity. Hear Res. 2002;169(1-2):47-55.

60. Lundquist PG, Wersäll J. Kanamycin-induced changes in cochlear hair cells of the guinea pig.
Z Zellforsch Mikrosk Anat. 1966;72(4):543-561.

61. Bagger-Sjöbäck D, Wersäll J. Gentamicininduced mitochondrial damage in inner ear sensory cells of the lizard Calotes versicolor. Acta Otolaryngol. 1978;86(1-2):35-51.

62. Lemasters JJ, Theruvath TP, Zhong Z, Nieminen AL. Mitochondrial calcium and the permeability transition in cell death. Biochim Biophys Acta. 2009;1787(11):1395-1401.

63. Chen FQ, Zheng HW, Schacht J, Sha SH. Mitochondrial peroxiredoxin 3 regulates sensory cell survival in the cochlea. PLoS One. 2013;8(4):e61999.

64. Daiber A. Redox signaling (cross-talk) from and to mitochondria involves mitochondrial pores and reactive oxygen species. Biochim Biophys Acta. 2010;1797(6-7):897-906.

65. Laight DW, Andrews TJ, Haj-Yehia AI, Carrier MJ, Anggård EE. Microassay of superoxide anion scavenging activity in vitro. Environ Toxicol Pharmacol. 1997;3(1):65-68.

66. Liang HL, Sedlic F, Bosnjak Z, Nilakantan V. SOD1 and MitoTEMPO partially prevent mitochondrial permeability transition pore opening, necrosis, and mitochondrial apoptosis after ATP depletion recovery. Free Radic Biol Med. 2010;49(10):1550-1560.

67. Yamada J, et al. Cell permeable ROS scavengers, Tiron and Tempol, rescue PC12 cell death caused by pyrogallol or hypoxia/reoxygenation. Neurosci Res. 2003;45(1):1-8.

68. Au S, Weiner ND, Schacht J. Aminoglycoside antibiotics preferentially increase permeability in phosphoinositide-containing membranes: a study with carboxyfluorescein in liposomes. Biochim Biophys Acta. 1987;902(1):80-86.

69. Forge A, Zajic G, Davies S, Weiner N, Schacht J. Gentamicin alters membrane structure as shown by freeze-fracture of liposomes. Hear Res. 1989;37(2):129-139.

70. Lipsky JJ, Lietman PS. Neomycin inhibition of adenosine triphosphatase: evidence for a neomycin-phospholipid interaction. Antimicrob Agents Chemother. 1980;18(4):532-535.

71. Sastrasinh M, Knauss TC, Weinberg JM, Humes HD. Identification of the aminoglycoside binding site in rat renal brush border membranes. J Pharmacol Exp Ther. 1982;222(2):350-358.

72. Schacht J. Purification of polyphosphoinositides by chromatography on immobilized neomycin. JLipid Res. 1978;19(8):1063-1067.

73. Priuska EM, Schacht J. Formation of free radicals by gentamicin and iron and evidence for an iron/gentamicin complex. Biochem Pharmacol. 1995;50(11):1749-1752.

74. Lesniak W, Harris WR, Kravitz JY, Schacht J, Pecoraro VL. Solution chemistry of copper(II)-gentamicin complexes: relevance to metal-related aminoglycoside toxicity. Inorg Chem. 2003;42(5):1420-1429.

75. Lesniak W, Pecoraro VL, Schacht J. Ternary complexes of gentamicin with iron and lipid catalyze formation of reactive oxygen species. Chem Res Toxicol. 2005;18(2):357-364.

76. Ibrahim WH, Habib HM, Kamal H, St Clair DK, Chow CK. Mitochondrial superoxide mediates labile iron level: evidence from Mn-SOD-transgenic mice and heterozygous knockout mice and isolated rat liver mitochondria. Free Radic Biol Med. 2013;65:143-149.

77. Naranuntarat A, Jensen LT, Pazicni S, Penner-Hahn JE, Culotta VC. The interaction of mitochondrial iron with manganese superoxide dismutase. J Biol Chem. 2009;284(34):22633-22640.

78. Murphy MP, Smith RA. Targeting antioxidants to mitochondria by conjugation to lipophilic cations. Annu Rev Pharmacol Toxicol. 2007;47:629-656.

79. Farris HE, LeBlanc CL, Goswami J, Ricci AJ. Probing the pore of the auditory hair cell mechanotransducer channel in turtle. J Physiol (Lond). 2004;558(pt 3):769-792.

80. Belenky P, et al. Bactericidal antibiotics induce toxic metabolic perturbations that lead to cellular damage. Cell Rep. 2015;13(5):968-980.

81. Dwyer DJ, Kohanski MA, Hayete B, Collins JJ. Gyrase inhibitors induce an oxidative damage cellular death pathway in Escherichia coli. $\mathrm{Mol}$ Syst Biol. 2007;3:91.

82. Lobritz MA, et al. Antibiotic efficacy is linked to bacterial cellular respiration. Proc Natl Acad Sci U S A. 2015;112(27):8173-8180.

83. Hutchin T, et al. A molecular basis for human hypersensitivity to aminoglycoside antibiotics. Nucleic Acids Res. 1993;21(18):4174-4179.

84. Hong S, Harris KA, Fanning KD, Sarachan KL, Frohlich KM, Agris PF. Evidence that antibiotics bind to human mitochondrial ribosomal RNA has implications for aminoglycoside toxicity. J Biol Chem. 2015;290(31):19273-19286.

85. Huth ME, et al. Designer aminoglycosides prevent cochlear hair cell loss and hearing loss. JClin Invest. 2015;125(2):583-592.

86. Tadros SF, D'Souza M, Zhu X, Frisina RD. Gene expression changes for antioxidants pathways in the mouse cochlea: relations to age-related hearing deficits. PLoS One. 2014;9(2):e90279.

87. Xie J, Talaska AE, Schacht J. New developments in aminoglycoside therapy and ototoxicity. Hear Res. 2011;281(1-2):28-37.

88. Kowaltowski AJ, Netto LE, Vercesi AE. The thiol-specific antioxidant enzyme prevents mitochondrial permeability transition. Evidence for the participation of reactive oxygen species in this mechanism. J Biol Chem. 1998;273(21):12766-12769.

89. Marí M, Morales A, Colell A, García-Ruiz C, Fernández-Checa JC. Mitochondrial glutathione, a key survival antioxidant. Antioxid Redox Signal. 2009;11(11):2685-2700.

90. Marí M, Morales A, Colell A, García-Ruiz C, Kaplowitz N, Fernández-Checa JC. Mitochondrial glutathione: features, regulation and role in disease. Biochim Biophys Acta. 2013;1830(5):3317-3328.

91. Nordberg J, Arnér ES. Reactive oxygen species, antioxidants, and the mammalian thioredoxin system. Free Radic Biol Med. 2001;31(11):1287-1312.

92. Karasawa T, Steyger PS. Intracellular mechanisms of aminoglycoside-induced cytotoxicity. Integr Biol (Camb). 2011;3(9):879-886.

93. Wibowo I, Pinto-Teixeira F, Satou C, Higashijima S, López-Schier H. Compartmentalized Notch signaling sustains epithelial mirror symmetry. Development. 2011;138(6):1143-1152.

94. Obholzer N, et al. Vesicular glutamate transporter 3 is required for synaptic transmission in zebra- 
fish hair cells. J Neurosci. 2008;28(9):2110-2118. 95. Steyger PS, Burton M, Hawkins JR, Schuff NR, Baird RA. Calbindin and parvalbumin are early markers of non-mitotically regenerating hair cells in the bullfrog vestibular otolith organs. Int J Dev Neurosci. 1997;15(4-5):417-432.

96. Raible DW, Kruse G. Organization of the lateral lien system in embryonic zebrafish. JComp Neurol. 2000;421(2):189-198.

97. Aarts E, Verhage M, Veenvliet JV, Dolan CV, van der Sluis S. A solution to dependency: using multilevel analysis to accommodate nested data. Nat Neurosci. 2014;17(4):491-496.

98. Galbraith S, Daniel JA, Vissel B. A study of clus- tered data and approaches to its analysis. JNeurosci. 2010;30(32):10601-10608.

99. Moen EL, Fricano-Kugler CJ, Luikart BW, O'Malley AJ. Analyzing clustered data: why and how to account for multiple observations nested within a study participant? PLoS One. 2016;11(1):e0146721. 